\title{
ANALISIS SISTEM INFORMASI PENDATAAN REKAM MEDIS PASIEN PENGGUNA BPJS PADA KLINIK ROHMATAN NUR AL AMIM
}

\author{
Hendra Mayatopani ${ }^{1}$, Nurdiana Handayani ${ }^{2}$, Yanuar Eka Ramadhan ${ }^{3}$ \\ 1,2,3 Fakultas Teknik Program Studi Informatika, Universitas Muhammadiyah Tangerang \\ 1 email: mayatopani@ft-umt.ac.id, 2email: nurdiana.handayani@ft-umt.ac.id ,
}

3email: yanuarekaramadhan666@gmail.com

\author{
Article history \\ Received Sep 2, \\ 2020 \\ Revised Okt 13, \\ 2020 \\ Accepted Nov 28, \\ 2020 \\ Available online Nov \\ 30,2020 \\ Keywords \\ Sistem Informasi, \\ Pelayanan, Rekam \\ Medis, Primary \\ Care, BPJS.
}

\begin{abstract}
Klinik Rohmatan Nur Al Amim akan selalu menjaga dan meningkatkan derajat kesehatan masyarakat melalui pelayanan yang bermutu dengan biaya terjangkau. Pengelolaan data di institusi pelayanan kesehatan merupakan salah satu komponen yang penting dalam mewujudkan sistem informasi klinik. Aplikasi Primary Care (Pcare) merupakan sebuah sistem informasi yang di rancang dan dikembangkan untuk melayani pasien pengguna BPJS Kesehatan. Aplikasi Pcare ini telah digunakan di Klinik Rohmatan Nur Al Amim sejak tahun 2010. Dengan aplikasi tersebut Klinik Rohmatan Nur Al Amim dapat melakukan mendata atau mencatat rekam medis terhadap pasien-pasien yang menggunakan BPJS pada saat berobat. Analisis yang dilakukan pada sistem Primary Care (Pcare), membahas proses pendataan rekam medis pasien BPJS yang berobat di Klinik Rohmatan Nur Al Amim.
\end{abstract}

\section{Abstrak}

Rohmatan Nur Al Amim Clinic will always maintain and improve the degree of public health through quality services at affordable costs. Data management in health service institutions is one important component in realizing clinical information systems. Application Primary Care (Pcare) is an information system designed and developed to serve patient users BPJS Health. Application Pcare it has been used at the Rohmatan Nur Al Amim Clinic since 2010. With the application, Rohmatan Nur Al Amim Clinic can record or record medical records of patients who use BPJS at the time of treatment. Analysis conducted on the system Primary Care (Pcare), discuss the process of collecting medical records of patients BPJS who went to the Rohmatan Nur Al Amim Clinic.

\section{PENDAHULUAN}

Perkembangan Teknologi Informasi pada zaman ini sangat lah berpengaruh pada kemajuan suatu organisasi. Teknologi informasi memberikan sebuah kecepatan dan keakuratan dalam melakukan pengolahan data bila dibandingkan dengan cara manual. Tuntutan pelayanan informasi dan pengelolaan informasi secara terintegrasi menjadi sangat penting di setiap lembaga termasuk di suatu klinik. Klinik sebagai salah satu institusi pelayanan kesehatan umum membutuhkan keberadaan sistem informasi yang akurat dan handal, serta cukup memadai untuk meningkatkan pelayanan kesehatan kepada para pasien serta lingkungan yang terkait lainnya. Pengelolaan data di institusi pelayanan kesehatan merupakan salah satu komponen yang penting dalam mewujudkan sistem informasi klinik. Dalam kehidupan manusia saat ini perkembangan ilmu pengetahuan teknologi berkembang sangat pesat, khususnya dibidang teknologi informasi. Dengan berkembangnya teknologi informasi semakin memudahkan manusia dalam melakukan aktifitas. Salah satunya dalam bidang kesehatan saat ini penggunaan sistim informasi dapat membantu kelancaran proses kegiatan yang sebelumnya dalam pencatatan rekam medis menggunakan aplikasi primary cary.

$$
\text { Aplikasi Primary Care (Pcare) }
$$
merupakan sebuah sistem informasi yang di rancang dan dikembangkan untuk melayani 
pasien pengguna BPJS Kesehatan. Aplikasi Pcare ini telah digunakan di Klinik Rohmatan Nur Al Amim sejak tahun 2010. Dengan aplikasi tersebut Klinik Rohmatan Nur Al Amim dapat melakukan mendata atau mencatat rekam medis terhadap pasien-pasien yang mengguna BPJS pada saat berobat. Rekam medis adalah fakta yang diberikan dengan keadaan pasien, riwayat penyakit dan pengobatan masa lalu serta saat ini yang ditulis oleh proses kesehatan memberikan pelayanan kepada pasien tersebut. Rekam medis berisi berkas catatan dan dokumen tentang identitas anamnesis, pemeriksaan, diagnose pengobatan, tindakan dan pelayanan lain yang diberikan pada seorang pasien selama diperiksa. Rekam medis dapat menunjang peningkatan pelayanan kesehatan dengan menyajikan administrasi yang tertib.

Klinik Rohmatan Nur Al Amim melayani tindakan medis seperti kecelakaan ringan, pemeriksaan kehamilan, $\mathrm{kb}$ dan penyakit - penyakit umum seperti batuk, pilek, demam, jumlah pasien yang ingin berobat per harinya dapat mencapai 80-100 pasien BPJS, hal ini dapat mengakibatkan penumpukan data rekam medis pasien BPJS pada Klinik Rohmatan Nur Al Amim yang dikarenakan masih sering terjadinya eror pada aplikasi Primary Care, sehingga pegawai harus melakukan pendataan pasien satu persatu terlebih dahulu secara manual dicatat pada kertas, kemudian dipanggil pasien tersebut satu persatu untuk selanjutnya dilakukan pemeriksaan oleh dokter, maka yang terjadinya timbulnya penumpukan data rekam medis pasien BPJS dan pegawai membutuhkan waktu kembali untuk melakukan pendataan semua pasien BPJS yang berobat pada Klinik Rohmatan Nur Al Amim.

\subsection{Indentifikasi Masalah}

Dari latar belakang diatas, penulis menemukan beberapa masalah diantaranya:

1. Adanya penumpukan data rekam medis pasien pengguna BPJS pada sistem informasi ketika berobat.

2. Sering terjadinya error pada saat login dan memasukan data hingga terjadi loading yang begitu lama.

3. Kurangnya pegawai yang dibutuhkan di Klinik Rohmatan Nur Al Amim.

\subsection{Rumusan Masalah}

Setelah melihat latar belakang di atas maka penulis mengambil beberapa rumusan masalah, yaitu :

1. Bagaimana proses berjalannya sistem yang digunakan untuk membantu pelayanan terhadap pasien pada Klinik Rohmatan Nur Al Amim?

2. Bagaimana sistem pendataan pasien pengguna BPJS pada Klinik Rohmatan Nur Al Amim?

3. Bagaimana peran PIC (Person In Charge) yang menggunakan sistem dalam proses pelayanan terhadap pasien pada Klinik Rohmatan Nur Al Amim?

\section{KAJIAN LITERATUR DAN PEGEMBANGAN HIPOTESIS (JIKA ADA)}

Menurut Muhamad Muslihudin dan Oktafianto (2016:27), analisis sistem adalah sebuah istilah yang secara kolektif mendeskripsikan fase-fase awal pengembangan sistem. Analisis sistem adalah teknik pemecahan masalah yang menguraikan bagian-bagian komponen tersebut bekerja dan berinteraksi untuk mencapai tujuan mereka. Analisis sistem merupakan tahapan paling awal dari pengembangan sistem yang dihasilkan nantinya. Tahapan ini sangat penting karena menentukan bentuk sistem yang harus dibangun. Tahapan ini bisa merupakan tahap yang mudah jika klien sangat paham dengan masalah yang dihadapi dalam organisasinya dan tahu betul fungsionalitas sistem informasi yang akan dibuat. Tetapi tahap ini bisa menjadi tahap paling sulit jika klien tidak bisa mengidentifikasi kebutuhannya dan tertutup terhadap pihak luar yang ingin mengetahui detail proses-proses bisnisnya.

BPJS ialah badan hukum yang dibentuk untuk menyelenggarakan program jaminan sosial, yang mulai beroperasi pada tanggal 01 januari 2014. BPJS terdiri dari BPJS 
Kesehatan dan BPJS Ketenagakerjaan. Dalam

PERMENKES No: 269 MENKES / PER /

\begin{tabular}{|c|c|l|}
\hline No & Judul Dan Penulis Jurnal & \multicolumn{1}{c|}{ Hasil Pembahasan } \\
\hline 1 & $\begin{array}{c}\text { Evaluasi Implementasi Aplikasi Primary Care (Pcare) di Klinik Laras } \\
\text { Hati, (Agung Kurniawan, Denny Adrian Mustika, Rizal Chandra } \\
\text { Muhammad, Susanti Catur Putri, 2018). }\end{array}$ & $\begin{array}{l}\text { Hasil yang di peroleh adalah menjelaskan } \\
\text { bagaimana kinerja aplikasi primary care } \\
\text { pada klinik Laras Hati. }\end{array}$ \\
\hline 2 & $\begin{array}{c}\text { Dampak pelayanan badan penyelenggara jaminan sosial kesehatan } \\
\text { terhadap masyarakat di kelurahan tingkulu, (Andreas G. Ch. Tampi, } \\
\text { Evelin J.R. Kawung, Juliana W. Tumiwa, 2016) }\end{array}$ & $\begin{array}{l}\text { Hasil yang di peroleh adalah menjelaskan } \\
\text { pelayanan BPJS sudah cukup baik tetapi } \\
\text { belum professional karena masih banyak } \\
\text { keluhan dari peserta BPJS. }\end{array}$ \\
\hline 3 & $\begin{array}{c}\text { Muhammadiyah Medical Center (MMC) Universitas Muhammadiyah } \\
\text { Surakarta, (Noor Alis Setiyadi, Fahmi Hakam, 2015) }\end{array}$ & $\begin{array}{l}\text { Hasil yang di peroleh adalah menjelaskan } \\
\text { bagaimana sistem informasi pada klinik } \\
\text { MMC. }\end{array}$ \\
\hline
\end{tabular}

Peraturan Menteri Kesehatan Nomor 749a/Menkes/per/XII/1989 tentang Rekam medis, dijelaskan bahwa rekam medis merupakan berkas yang berisikan catatan dan dokumen tentang identitas pasien, pemeriksaan, pengobatan, tindakan dan pelayanan lain kepada pasien pada sarana pelayanan kesehatan. Dalam penjelasan Pasal 46 ayat (1) UU No. 29 Tahun 2004 tentang Praktik Kedokteran, yang dimaksud dengan rekam medis adalah berkas yang berisi catatan dan dokumen tentang identitas pasien, pemeriksaan, pengobatan, tindakan dan pelayanan lain yang telah di berikan kepada pasien. Kemudian diperbaharui dengan PERMENKES No : 269/MENKES/PER/III/2008 yang dimaksud rekam medis adalah berkas yang berisi catatan dan dokumen antara lain identitas pasien, hasil pemeriksaan, pengobatan yang telah diberikan, serta tindakan dan pelayanan lain yang telah diberikan kepada pasien. Kedua pengertian rekam medis tersebut menunjukkan perbedaan yaitu Permenkes Nomor 749a/Menkes/Per/XII/1989 hanya menekankan pada sarana pelayanan kesehatan, sedangkan dalam UU Praktik Kedokteran tidak. Ini menunjukan pengaturan rekam medis pada UU Praktik Kedokteran lebih luas, berlaku baik untuk sarana kesehatan maupun diluar sarana kesehatan. Namun dengan terbitnya
III / 2008 sudah tidak ada perbedaan lagi.

Tabel 1. Perkembangan penulisan mengenai sistem informasi Kesehatan 


\section{METODE PENELITIAN}

Berikut tahapan dalam melakukan penelitian :
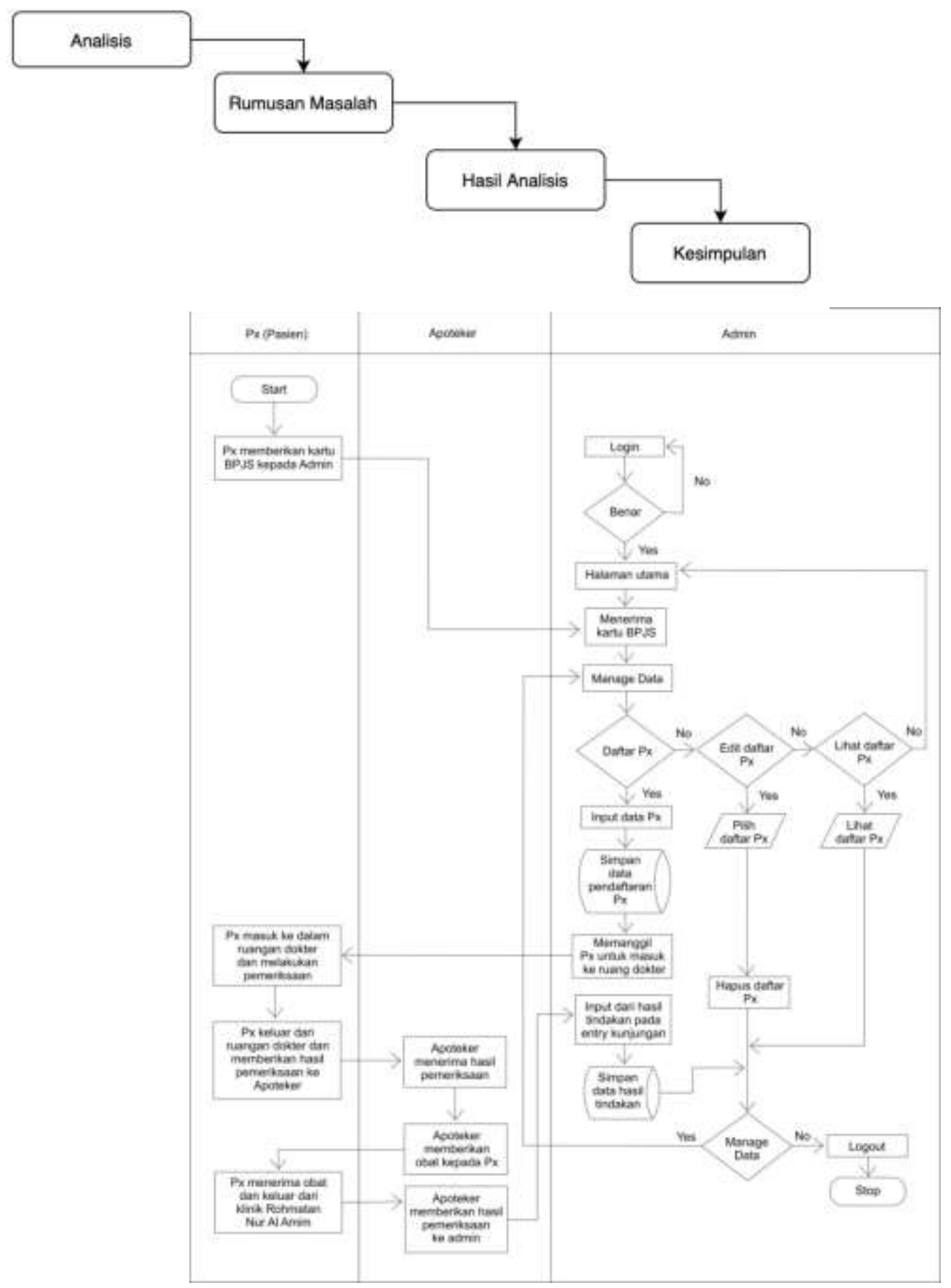

Gambar 2. Flowchart Klinik Rohmatan Nur Al Amim 


\section{HASIL DAN PEMBAHASAN}

Prosedur yang berjalan pada klinik

A. Pasien - Memberikan kartu BPJS kepada admin, melakukan pemeriksaan dengan dokter untuk mendapatkan hasil pemeriksaan yang akan diberikan kepada apoteker, dan mendapatkan obat sesuai dengan resep dokter yang diberikan.

B. Admin - Menerima kartu BPJS pasien dengan memasukan nomor yang terdapat pada kartu bpjs pasien memastikan faskes pasien berada di Klinik Rohmatan Nur Al Amim, menyimpan data pasien yang ingin berobat

C. Apoteker - Menerima resep obat dari pasien yang sudah diberikan dokter dan memberikan obatnya ke pasien, lalu memberikan data pasien tersebut ke admin, dan admin menginputya pada aplikasi primary care.

\section{Fungsi dan Kegunaan Sistem}

\section{Sistem Informasi Klinik}

Sistem informasi klinik berfungsi untuk menginput rekam medis pasien dan melihat riwayat data rekam medis sebelumnya serta tindakan yang akan diberikan selanjutnya.

\section{Kegunaan Sistem Informasi}

Sistem yang diterapkan disini berguna untuk mempermudah dalam mencari data pasien bpjs, mendata pasien bpjs, melihat riwayat berobat pasien bpjs yang dibutuhkan oleh klinik.

\section{Cara kerja sistem}

\section{Input}

Proses input pada sistem Primary Care pada Klinik Rohmatan Nur Al Amim adalah sebagai berikut :

\section{Admin}

Menginput data pasien pengguna bpjs yang ingin berobat, dengan memasukan nomor bpjs pada form pencarian di aplikasi, dan memasukan data rekam medis pasien setelah pemeriksaan yang diberikan oleh apoteker.

\section{Proses}

Dimana suatu input yang sudah di lakukan oleh admin akan di kelola menjadi output oleh sistem.

\section{Admin}

Update data rekam medis pasien bpjs yang sudah di input.

Proses output pada sistem Primary Care pada Klinik Rohmatan Nur Al Amim adalah sebagai berikut :

\section{Admin}

Output yang di hasilkan adalah informasi data rekam medis pasien BPJS yang sudah ter update pada riwayat pelayanan pasien dan riwayat pendaftaran pasien.

\section{Gambaran sistem informasi yang berjalan} Gambaran sistem informasi yang berjalan di buat dalam diagram UML pada Klinik Rohmatan Nur Al Amim, berikut adalah diagram UML dan penjelasannya :

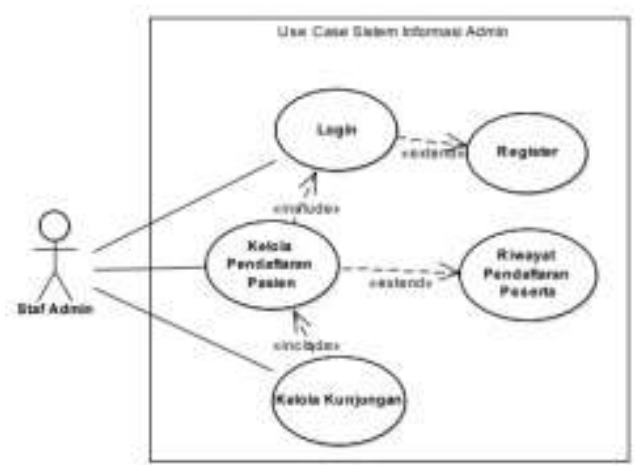

Gambar 3. Use case Admin 


\section{Diagram Aktivitas}

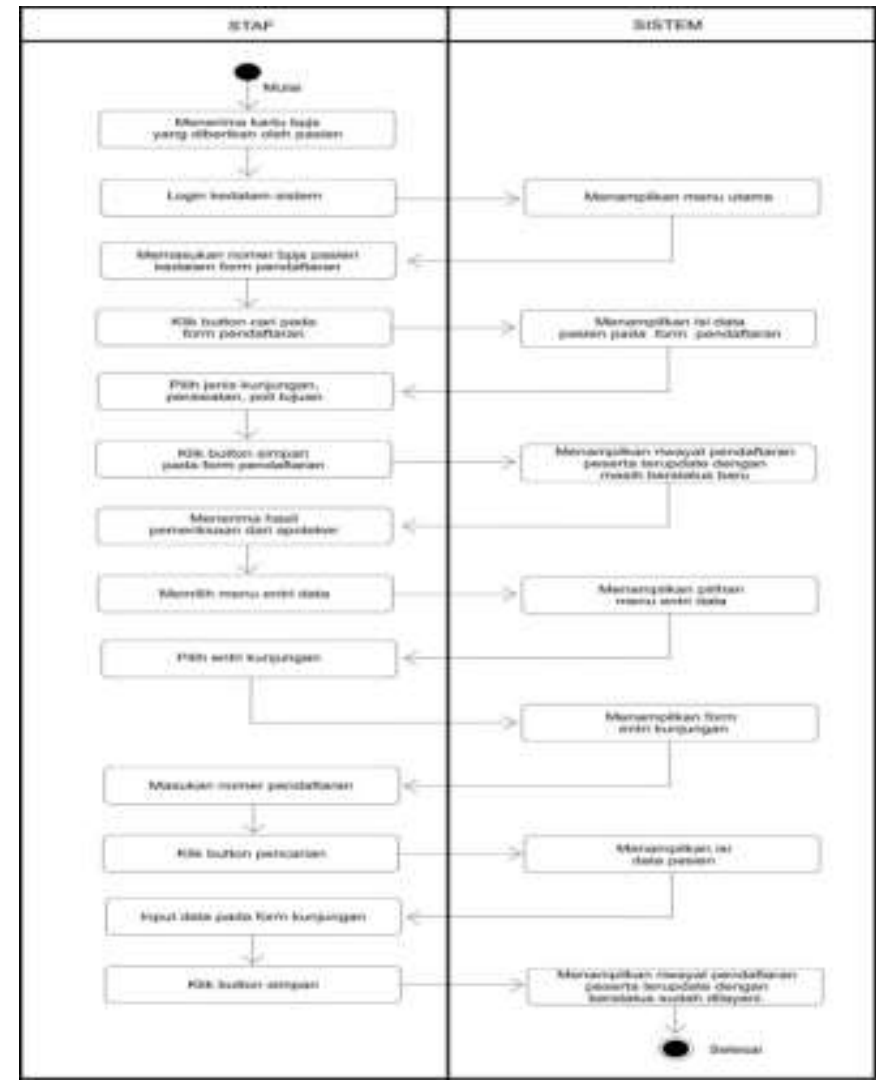

Gambar 4. Aktivitas diagram admin

\section{Antarmuka sistem informasi yang berjalan}

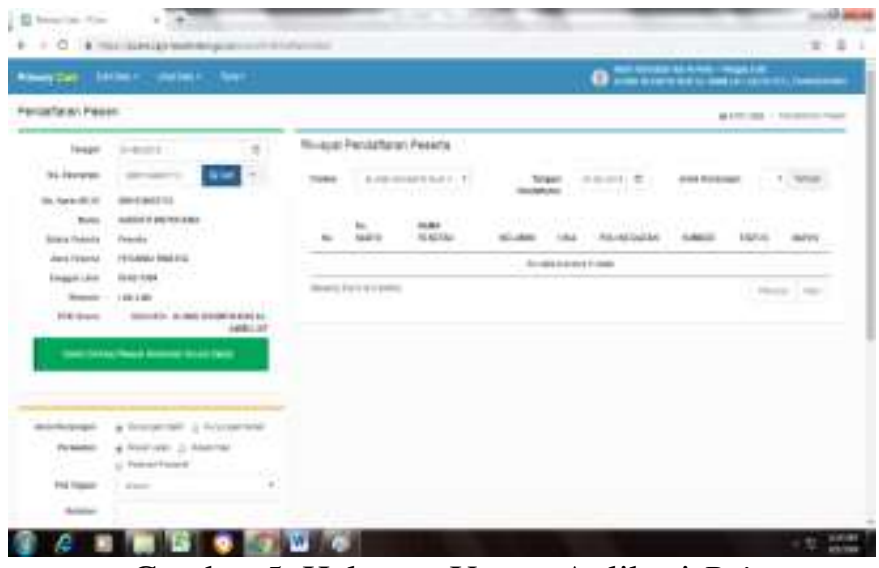

Gambar 5. Halaman Utama Aplikasi Primary

Care

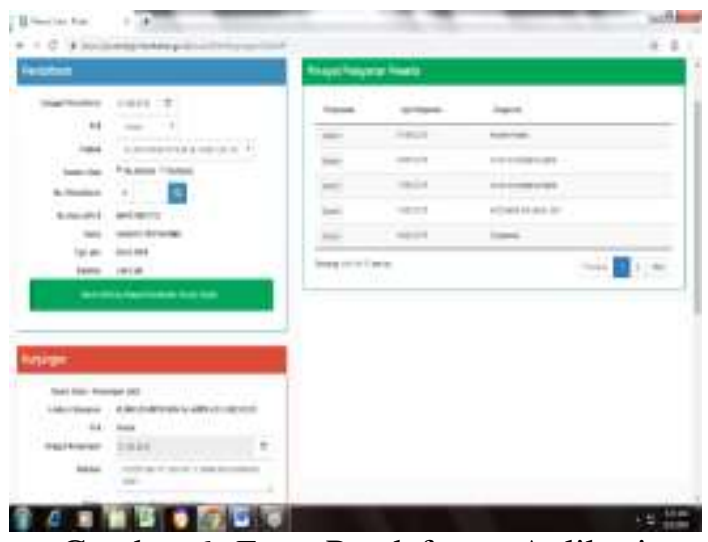

Gambar 6. Form Pendaftaran Aplikasi Primary Care

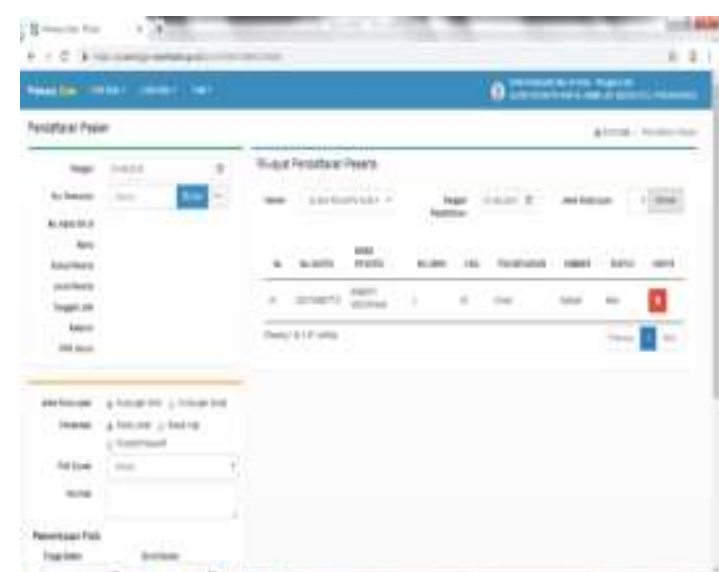

Gambar 7. Halaman Pelayanan

Pasien Aplikasi Primary Care 


\section{Eror yang terjadi pada sistem}

Berdasarkan analisis yang telah dilakukan di Klinik Rohmatan Nur Al Amim menunjukan bahwa Aplikasi Primary Care yang digunakan di Klinik Rohmatan Nur Al Amim masih sering mengalami error dan loading lama. Hal tersebut dapat dibuktikan dengan hasil wawancara yang dilakukan kepada beberapa pengguna aplikasi Primary Care di Klinik Rohmatan Nur Al Amim.

Tabel 2 Penjelasan Eror Pada Aplikasi

\begin{tabular}{|c|l|l|}
\multicolumn{3}{|c}{ Primary Care } \\
\hline No & $\begin{array}{l}\text { Kondisi } \\
\text { Error Pada } \\
\text { Sistem }\end{array}$ & $\begin{array}{l}\text { Eror Yang } \\
\text { Terjadi }\end{array}$ \\
\hline \multirow{1}{*}{1} & $\begin{array}{l}\text { Terkendala } \\
\text { jika akses ke } \\
\text { server, server } \\
\text { penuh atau } \\
\text { banyaknya } \\
\text { yang } \\
\text { Sistem } \\
\text { akan } \\
\text { terjadi } \\
\text { error } \\
\text { diwaktukan } \\
\text { akses ke } \\
\text { waktu } \\
\text { tertentu }\end{array}$ & $\begin{array}{l}\text { dalam server } \\
\text { dan menjadi } \\
\text { load yang } \\
\text { begitu lama. }\end{array}$ \\
\hline
\end{tabular}

Berdasarkan rekapitulasi hasil wawancara yang di lakukan kepada 5 responden pengguna aplikasi Primary Care di Klinik Rohmatan Nur Al Amim yaitu menyatakan aplikasi Primary Care di Klinik Rohmatan Nur Al Amim sering mangalami error dan loading lama.

\section{KESIMPULAN}

Berdasarkan uraian, dapat ditarik kesimpulan sebagai akhir dari pembahasan sebagai berikut :

1. Sistem informasi yang digunakan pada Klinik Rohmatan Nur Al Amim yaitu aplikasi Primary Care, sudah sangat membantu dalam melakukan pendataan pasien pengguna BPJS yang ingin berobat pada Klinik Rohmatan Nur Al Amim.

2. Pada sistem pendataan pasien pengguna BPJS yaitu aplikasi Primary Care, masih terdapat terjadinya error pada saat $\log$ in dan meng input diagnosa pada form kunjungan aplikasi Primary Care, sehingga membutuhkan waktu untuk $\log$ in kembali dan menginput data form kunjungan.

3. Terdapat bagian admin yang masih belum tetap, pada bagian input data rekam medis pasien BPJS tersebut masih dilakukan secara bergantian (Perawat/Bidan).

\section{REFERENSI}

Andreas G. Ch. Tampi, Evelin J.R. Kawung, dan Juliana W. Tumiwa, 2016, Dampak Pelayanan Badan Penyelenggara Jaminan Sosial Kesehatan Terhadap Masyarakat Di Kelurahan Tingkulu, e-journal "Acta Diurna" Volume V. No.1. Tahun 2016. BPJS Kesehatan - Seputar BPJS Kesehatan Minggu 14 Juli 2019 https://bpjskesehatan.go.id/bpjs/dmdocuments/ea c4e7a830f58b4ade926754f74b6caf.pd f

Handayani, N., Septarini, R. S., Mayatopani, H., \& Sudarsono, I. (2020). Sistem Ujian Rating Berbasis Web Untuk Personil Pemandu Lalu Lintas Udara (Studi Kasus Airnav Indonesia). Jurnal Inovasi Informatika, 5(1), 72-82.

Yanuardi, Yanuardi, and Rachmat Destriana. "PERANCANGAN SISTEM INFORMASI PENJUALAN ONLINE GAS DALAM STRATEGI EBUSINESS MENGGUNAKAN ANALISIS SWOT." JIKA (Jurnal Informatika) 4.1 (2020): 1-6.

Indrajani, S.kom., MM, 2015, Database Design (Case Study All In One): Cara Praktis Belajar Perancangan Basis Data Dengan Cepat, Tepat, dan Jelas. Jakarta: Penerbit Elex Media Komputindo.

Muhammad Muslihudin Oktafianto, Yakub, Edhy Sutanta, 2016, Analisis dan Perancangan Sistem Informasi: Menggunakan Model Terstruktur dan UML. Yogyakarta: Penerbit Andi. 
Liesnaningsih, L., Taufiq, R., Destriana, R., \&

Suyitno, A. P. (2020). Sistem

Pendukung Keputusan Penerima

Beasiswa Berbasis WEB

Menggunakan Metode Simple Additive

Weighting (SAW) pada Pondok

Pesantren Daarul Ahsan. Jurnal

Informatika Universitas

Pamulang, 5(1), 54-60.

Prof. Dr. Sri Mulyani, Ak., CA, Romney dan Steinbart, 2016, Metode Analisis dan Perancangan Sistem. Bandung:

Penerbit Abdi Sistematika. 